\title{
Prevalence of musculoskeletal pain and associated disability among professional bus drivers: a cross-sectional study
}

\author{
Apirati Kasemsan $^{1} \cdot$ Leonard Joseph $^{2}\left(\mathbb{D} \cdot\right.$ Aatit Paungmali $^{1} \cdot$ Patraporn Sitilertpisan ${ }^{1} \cdot$ Ubon Pirunsan $^{1}$
}

Received: 5 October 2020 / Accepted: 8 January 2021 / Published online: 15 April 2021

(c) The Author(s), under exclusive licence to Springer-Verlag GmbH Germany, part of Springer Nature 2021

\begin{abstract}
Purpose Professional bus drivers risk developing musculoskeletal pain (MSP) and disability due to their working condition. The current study investigates the prevalence rate of MSP and disability among professional bus drivers.

Methods A cross-sectional study was conducted among 83 professional bus drivers. The prevalence rate of MSP was evaluated using a standardized Nordic musculoskeletal questionnaire. The disabilities due to the MSP were evaluated using neck disability index (NDI), Oswestry disability index (ODI) and shoulder pain and disability index (SPADI) tools. Prevalence of MSP was presented with 95\% of confidence interval (CI) at an alpha level of 0.05 . The 12 months and 7 days prevalence of MSP were tabulated for analysing the trend of MSP between the upper and lower body regions.

Results The drivers had a mean driving experience of $10.07 \pm 7.26$ years. The mean driving hours/week were $50.25 \pm 12.82 \mathrm{~h}$. Neck and back were the most affected regions with a prevalence rate of $81.9 \%(N=68)$ and $80.7 \%(N=67)$ at 12 months. Back region recorded the highest 7 days prevalence rate for MSP with 53\% $(N=44)$. Approximately one fourth of the bus drivers population $(23.9 \%, N=16)$ had moderate disability in back region. More than half with MSP in the neck region presented mild disability $(54.4 \%, N=37)$.

Conclusion The bus drivers reported a high prevalence rate of MSP in the neck, back and shoulder regions with mild to moderate disabilities. Appropriate health care and rehabilitation programs are necessary for the prevention and management of MSP among the bus drivers.
\end{abstract}

\section{Introduction}

Professional bus drivers form a major occupational group in transportation sector worldwide. Professional bus drivers are involved in an occupation that requires them to operate and drive buses for public transport over longer period of time. Higher rates of work-related musculoskeletal disorders (WRMSDs) are reported in the driving occupation, as per a health and safety executive report, 2015 from the United Kingdom (Health and Safety Executive (HSE) 2015). Another recent finding published by the US Bureau of Labor Statistics in 2017 indicates that bus drivers are one of the

Ubon Pirunsan

ubon.p@cmu.ac.th

1 Department of Physical Therapy, Faculty of Associated Medical Science, Chiang Mai University, Chiang Mai, Thailand

2 School of Health Sciences, University of Brighton, Robert Dodd Building, 49 Darley Road, Eastbourne BN20 7UR, East Sussex, UK top three occupations prone to have musculoskeletal disorders with highest incidence rates (206 per 10,000 fulltime workers (Bureau of Labor Statistics 2017). Data show that globally, WRMSDs account for $42 \%-58 \%$ of all workrelated illnesses and $40 \%$ of all work-related health costs (Abledu and Abledu 2012). The term WRMSDs are defined as impairments of the musculoskeletal system caused or aggravated primarily by work itself or by the environment in which work is performed (Abledu and Abledu 2012). In this study, WRMSDs among bus drivers was defined as musculoskeletal pain (MSP) reported by drivers in a professional working environment. In severe cases, the MSP could leads to significant discomfort with disability and hospitalization (Abledu et al. 2014).

Driving as an occupation involves bus drivers to use repetitive muscular effort to perform various occupational tasks such as using steering, changing gears and applying breaks continually and repeatedly. Often, the bus drivers work for longer shift hours resulting in continuous work without any rest or meal breaks (Wei et al. 2017). Also, bus drivers are exposed to challenging physical working 
conditions such as prolonger seated posture, awkward sitting positions, noise, temperature fluctuations and whole body vibration (Szeto and Lam 2007). Eventually, these challenging working conditions contributes to increase physical loading of the musculoskeletal system leading to MSP at their work (Szeto and Lam 2007). For instance, prolonged sitting and continuous vibration induces increased loading on the intervertebral discs, compressive forces on vertebral discs, greater creep in the lumbar soft tissues and back muscles fatigue, all of which will contribute to degenerative changes in the lumbar spine (Szeto and Lam 2007; Magnusson et al. 1996). Furthermore, sustained muscular effort required in the cervical region and as well as in the larger joints such as shoulders, hips and knees to manoeuvre the steering wheel and control pedals may stress the musculoskeletal system (Westgaard 2000). A bus driver is often constrained to the driver's cabin with very less room for flexing and moving the limbs which may aggravates muscle tension (John et al. 2006). All of these mechanisms may explain the reasons for bus drivers developing MSP at their work place. Figure 1 shows the characteristics of the buses used by bus drivers in the current research study. In addition, the specific characteristics and limitations of the buses used by the drivers were presented in Table 1.

Thailand has a convenient and well-developed public transport services with approximately 256,184 buses and 4,867,504 minibuses nationwide (World Health Organization 2018). Thus, bus drivers form an important occupational group in the Thailand transportation sector. To our knowledge, there is a paucity of literature that investigates the prevalence of MSP among the bus drivers in Thailand.
Lack or absence of any evidence on the musculoskeletal health of bus drivers remains as a challenge for occupational health clinicians and policy makers to develop any rehabilitation programs to support the health and welfare of bus drivers. An expert group on the work-related musculoskeletal disorders together with the local stakeholders such as the bus companies has been working on the Sustainable Model for Assessment and Rehabilitation Training (SMART Drive) project to combat musculoskeletal disorders among bus drivers. One of the aims of the SMART Drive project is to generate a dedicated data base on the prevalence of MSP among professional drivers among the developed and developing countries. Thus, the current study to investigate the prevalence of MSP was initiated in the Northern Thailand region with a plan of expanding nationwide and eventually to several other countries. Therefore, the main aim of this study was to investigate 12-month prevalence of the MSP and associated disability among bus drivers in the Northern Thailand region. The findings of the study may serve as a catalyst to organize and develop a nationwide comprehensive comparable database on the prevalence of MSP among bus drivers.

\section{Methods}

\section{Study design}

This cross-sectional study was conducted among professional bus drivers between the period 2019 and 2020. The bus drivers were from the northern Thailand region who had
Fig. 1 The characteristics of the buses used by the drivers in the research group

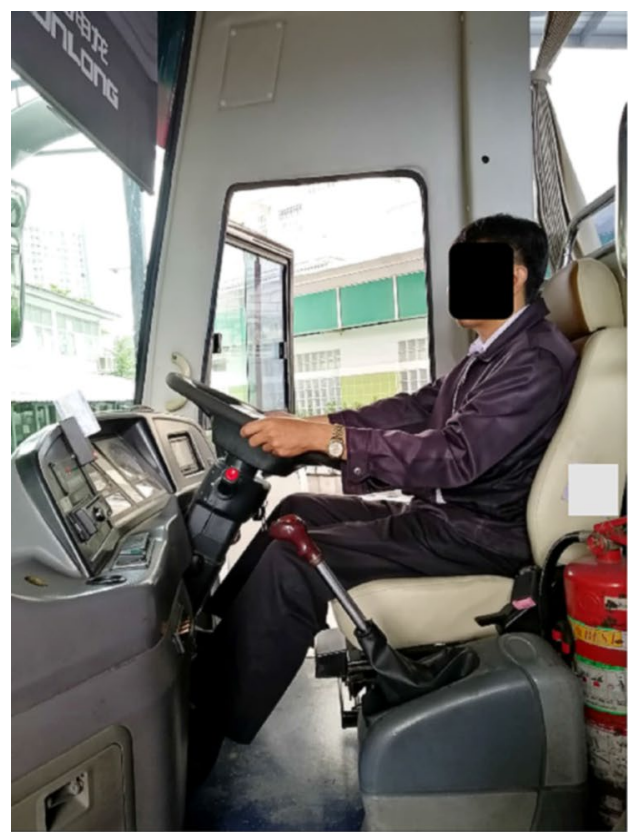

Buses with manual gear

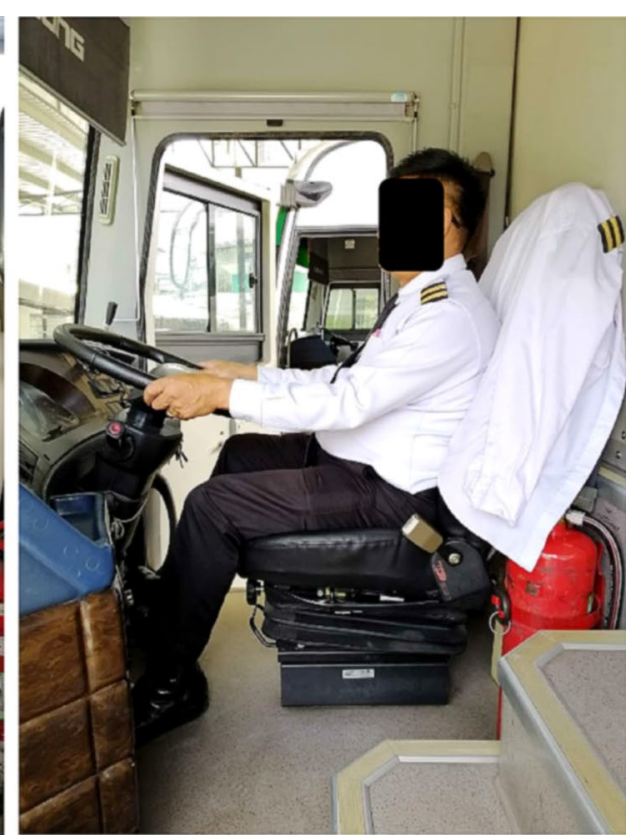

Buses with automatic gear 
Table 1 The specific characteristics and limitations of the buses used by the drivers in the research group

\begin{tabular}{|c|c|c|}
\hline Bus characteristics & $\begin{array}{l}\text { Buses with automatic gear - specific limita- } \\
\text { tions }\end{array}$ & Buses with manual gear- specific limitations \\
\hline $\begin{array}{l}\text { (1) The possibilities of adjusting the steering } \\
\text { wheel }\end{array}$ & 10 degrees available for adjustment & $\begin{array}{l}\text { Features for adjusting steering wheel not avail- } \\
\text { able }\end{array}$ \\
\hline (2) The seat height & Height could not be adjusted & Seat is fixed and could not be adjusted \\
\hline (3) The distance from the steering wheel & $\begin{array}{l}\text { Between } 30-40 \mathrm{~cm} \text { from steering wheel } \\
(10 \mathrm{~cm} \text { available for adjustment })\end{array}$ & $\begin{array}{l}\text { Between } 30-40 \mathrm{~cm} \text { from steering wheel }(10 \mathrm{~cm} \\
\text { available for adjustment) }\end{array}$ \\
\hline (4) Seat back angle position & Between 100-120 degrees & Between 100-120 degrees \\
\hline (5) Seat angle & Adjustable & Not adjustable \\
\hline (6) Support for the forearms & Not available & Not available \\
\hline $\begin{array}{l}\text { (7) Availability of addi- } \\
\text { tional space at the back of the seat }\end{array}$ & No extra space available & $\begin{array}{l}\text { Additional extra space not available at back of } \\
\text { seat }\end{array}$ \\
\hline (8) Total space of bus cabin & $\begin{array}{l}120 \times 120 \times 250 \mathrm{~cm} \\
\text { Additional extra space available on left side of } \\
\text { driving seat/driver }\end{array}$ & $\begin{array}{l}100 \times 120 \times 250 \mathrm{~cm} \\
\text { No additional extra space available on left side } \\
\text { of driver due to location of gear box }\end{array}$ \\
\hline (9) Type of seat cushion for driving seat & $\begin{array}{l}\text { Foamed seat cushion covered with artificial } \\
\text { leather }\end{array}$ & $\begin{array}{l}\text { Foamed seat cushion covered with fabric/artifi- } \\
\text { cial leather }\end{array}$ \\
\hline
\end{tabular}

been working in one of the three major bus companies in this region. A simple random selection procedure was adopted to select a bus company from a list of three major bus companies in the Northern Thailand region. The researchers contacted the bus company and the purpose of the research was explained to the bus company management office. The full list of the bus drivers were obtained from the bus company managers and the purpose of the study were explained to the drivers. As the SMART Drive project was geared towards establishing equal partnership and engagement approach with the participants and local stake holders (Manafò et al. 2018), the bus company management and the drivers were informed that a final study report and summary of findings would be shared at the completion of the study.

\section{Participant characteristics}

A total of 83 full time bus drivers with mean age of $44.9 \pm 7.2$ years and $7.8 \pm 1.9 \mathrm{~h}$ of driving duration per day participated in the study. The drivers were recruited based on a pre-defined inclusion and exclusion criteria. Participants who included (1) were between 30-60 years of age; (2) had a minimum of 1 year of professional bus driving experience with bus company; (3) were driving at least for a minimum of $5 \mathrm{~h}$ per working day; (4) was a permanent employee of the bus company working standard full time working hours of minimum $40 \mathrm{~h}$ per week; (5) were driving more than $160 \mathrm{~km}$ per day in the Chiang Mai region and surrounding locality bus routes network to ensure similar exposure to the driving terrain. Exclusion criteria includes any traumatic injuries or accidents sustained by the drivers prior to the starting of the job. Also, drivers who had sought medical help for any MSP prior to their occupation were excluded. The exclusion criteria in the study were set to determine work relatedness of the MSP reported by the drivers. A written informed was obtained from the drivers prior to the participation in the study. The study was ethically approved by a university institutional ethics committee (Ethical approval number: AMSEC-62EX-014) as per the Helsinki declarations.

\section{Study measures}

The individual characteristics of the participants such as history of smoking, history of drinking and body mass index (BMI) were calculated. The height of the participants were collected without shoes using a portable stadiometer. The body weight was calculated using a digital weighing scale. As per an established protocol, the BMI was calculated by dividing the weight $(\mathrm{kg})$ by height squared $\left(\mathrm{m}^{2}\right)$ and was rounded to the nearest $0.1\left(\mathrm{~kg} / \mathrm{m}^{2}\right)$ (Jitnarin et al. 2011). Body Mass Index (BMI) was categorized into four groups, Underweight: BMI < 18.5, Normal: BMI 18.5-22.9, Overweight: BMI 23-24.9 and Obese: $\mathrm{BMI} \geq 25$ according to Asia Pacific guidelines (World Health Organization 2000). In addition, occupational characteristics such as years of experience, number of driving hours per day and total numbers of driving hours per week were collected.

Standardized Nordic Musculoskeletal Questionnaire (SNMQ) was used to measure the prevalence of MSP among bus drivers. SNMQ is a valid tool to evaluate the prevalence of MSP over the period of the last 7 days and past 12 months (Crawford 2007). SNMQ use a body map which covers a total of nine body regions namely, neck, upper back, shoulder, elbows, wrists-hands, low back, hipthighs, knee and ankle-feet. The participants were asked to mark on an appropriate body regions in the SNMQ to 
indicate any presence or absence of MSP over the last 7 days and 12 months period of time.

The disability associated with the low back pain was measured using the Oswestry disability index (ODI) tool (Fairbank and Pynsent 2000). The ODI classify the disability into five categories according to the overall score and it is one of the commonly used tools to measure disability related to low back pain (Sheahan et al. 2015). The severity of disability according to the ODI scores were interpreted as minimal disability $(0-20 \%)$, moderate disability (21-40\%), severe disability (41-60\%), crippled (61-80\%) and bed bound (81-100\%) (Payares et al. 2011). The Neck disability index (NDI) was used to measure the disability associated with neck pain (MacDermid et al. 2009). The NDI sores were interpreted as follows to categorise the levels of disability: scores: $0-4$, no disability; 5-14, mild disability; $15-24$, moderate disability; $25-34$, severe disability; and greater than 35, complete disability (Vernon and Mior 1991). Lastly, the Shoulder Pain and Disability Index (SPADI) was used to measure current shoulder pain and disability (Breckenridge and McAuley 2011). The SPADI has 2 sub scales; a 5-item subscale that measures pain and an 8-item subscale that measures disability. The bus drivers were instructed to mark the number that best indicated their level of pain and extent of difficulty using the involved shoulder. The pain scale is summed up to a total of 50 while the disability scale sums up to 80 . The total SPADI score is expressed as a percentage with a higher score shows more disability (Breckenridge and McAuley 2011). A qualified physiotherapist interviewed the bus drivers in the bus company and administered the tool on work site to collect the data during an average working day.

\section{Statistical analysis}

The data obtained were analysed using Statistical Package for Social Science (SPSS) version 24 software. Data were checked for normality using the Kolmogorov-Smirnov test. A descriptive statistics was used to present the prevalence of MSP among bus drivers. The SNMQ data were presented according to different body regions and the MSP was presented for the last 7 days and 12 months. Prevalence of MSP for each body region was presented with $95 \%$ of confidence interval (CI) at an alpha level of 0.05. Furthermore, the 12 months and 7 days prevalence of MSP in both the spine and extremity were tabulated for further analysis of the trend of prevalence rate between the upper and lower body regions. Data on the ODI, NDI and SPADI were presented in mean and standard deviation if normally distributed, while median and interquartile range were presented if the normality of the data was not established.

\section{Result}

The drivers who participated in this study had a mean driving experience of $10.07 \pm 7.26$ years. The mean driving hours week were $50.25 \pm 12.82 \mathrm{~h}$. Approximately $36.1 \%(N=30)$ of the drivers were smokers. The demographic characteristics of the bus drivers were presented in Table 2. The results on the prevalence of MSP showed that the neck and back region were the most affected regions with a prevalence rate of $81.9 \%(N=68)$ and $80.7 \%(N=67)$ at 12 months. When the prevalence of MSP was measured over the past 7 days, back region recorded the highest prevalence rate of 53\% $(N=44)$ followed by neck $(49.4 \%, N=41)$ and shoulder region $(36.1 \%, N=30)$. Table 3 shows the prevalence rate of all the body regions reported among the bus drivers in the past 12 months and 7 days. The trend of the 7 days and 12 months prevalence rate of MSP in various body regions were illustrated in Fig. 2a and $\mathrm{b}$.

The severity of disability due to the MSP in the back and neck regions as evaluated by ODI and NDI scores were shown in Tables 4 and 5. Approximately one fourth of the population of bus drivers $(23.9 \%, N=16)$ had moderate disability with MSP in the back region while more than half of the population of bus drivers with MSP in the neck region presented mild disability $(54.4 \%, N=37)$. The severity of disability due to MSP in the shoulder region measured by SPADI total score was $40.75 \pm 24.71$ with

Table 2 Demographic characteristics of bus drivers

\begin{tabular}{ll}
\hline Characteristics & Mean \pm SD \\
\hline Age (years) & $44.18 \pm 7.20$ \\
Weight (kg) & $73.53 \pm 11.64$ \\
Height (centimeters) & $167.32 \pm 5.86$ \\
Body mass index & $26.23 \pm 3.63$ \\
Driving experience (years) & $10.07 \pm 7.26$ \\
Driving hours/day & $7.77 \pm 1.90$ \\
Driving hours/week & $50.25 \pm 12.82$ \\
Smoking & \\
Yes- $N(/ \%)$ & $30(36.1 \%)$ \\
No- $N(/ \%)$ & $53(63.8 \%)$ \\
Alcohol consumption & \\
Yes- $N(/ \%)$ & $55(66.3)$ \\
No- $N(/ \%)$ & $28(33.7)$ \\
Previous injury & \\
Yes- $N(/ \%)$ & $22(26.5 \%)$ \\
No- $N(/ \%)$ & $61(73.5 \%)$ \\
History of medication & \\
Yes- $N(/ \%)$ & $29(34.9 \%)$ \\
No- $N(/ \%)$ & $54(65.1 \%)$ \\
\hline
\end{tabular}


Table 3 Prevalence of musculoskeletal pain reported among bus drivers

\begin{tabular}{|c|c|c|c|c|}
\hline \multirow{2}{*}{$\begin{array}{l}\text { Total participants } \\
(N=83)\end{array}$} & \multicolumn{2}{|c|}{$\begin{array}{l}\text { MSP in the last } \\
12 \text { months }\end{array}$} & \multicolumn{2}{|c|}{$\begin{array}{l}\text { MSP in the past } \\
7 \text { days }\end{array}$} \\
\hline & $N$ & $\begin{array}{l}\text { Prevalence } \\
(95 \% \mathrm{CI})\end{array}$ & $N$ & $\begin{array}{l}\text { Prevalence } \\
(95 \% \mathrm{CI})\end{array}$ \\
\hline Neck & 68 & $81.9(72.3-88.7)$ & 41 & $49.4(38.9-59.9)$ \\
\hline Upper back & 42 & $50.6(40.1-61.1)$ & 29 & $35.0(25.5-45.6)$ \\
\hline Shoulders & 40 & $48.1(37.7-58.7)$ & 30 & $36.1(26.6-46.8)$ \\
\hline Elbows & 10 & $12.0(6.0-20.7)$ & 12 & $14.4(8.4-23.5)$ \\
\hline Wrists/hands & 28 & $33.7(24.4-44.4)$ & - & - \\
\hline Lower back & 67 & $80.7(70.9-87.7)$ & 44 & $53.0(42.3-63.3)$ \\
\hline Hips/thighs & 31 & $37.3(27.7-48.1)$ & 25 & $30.1(21.3-40.6)$ \\
\hline Knees & 36 & $43.3(33.2-54.1)$ & 25 & $30.1(21.3-40.6)$ \\
\hline Ankles/feet & 40 & $48.1(37.7-58.7)$ & 23 & $27.7(19.2-38.1)$ \\
\hline
\end{tabular}

MSP Musculoskeletal pain

$21.3 \pm 10.41$ for the SPADI pain and $19.45 \pm 16.73$ for the SPADI disability scores, respectively.

\section{Discussion}

To our knowledge, this was the first study that investigated MSP among long distance bus drivers in Thailand. As the SMART drive expert group approached the policy makers and stakeholders in Thailand to develop a work assessment and rehabilitation program for bus drivers with MSP, some preliminary evidence on the extent of the problem was required to initiate a sincere conversation with the relevant authorities. Therefore, the current study was conducted in the Northern Thailand region to have a preliminary understanding on the magnitude of prevalence of MSP among bus drivers. The initial evidence from the study findings showed that the prevalence of MSP among bus drivers were high especially in the back, neck and shoulder regions. Thus, the current study findings provided a meaningful platform to initiate positive collaborations with the concerned stakeholders and relevant local authorities. Effective stakeholder participation in setting research priorities are very important in framing sustainable management strategies (Clavisi et al. 2013). Also, engagement of stakeholders was suggested to improve care by facilitating stakeholders to play an active role and take accountability in the management of the condition (Carman et al. 2013). Therefore, the SMART drive group employed an equal partnership and engagement approach in the study design which was one of the unique feature of the current study. A researcher-stakeholderparticipant discussion forum on the research priorities and solutions on the MSP among bus drivers was halted due to
Covid-19 pandemic and it would be taking place sooner to discuss the findings of the study and further implications.

The study findings showed that the prevalence of MSP among bus drivers was higher than the global meta-prevalence of MSP in this occupational sector. Recently, a systematic review on the global meta-prevalence of MSP among professional drivers was conducted by the SMART drive group as there was a need to establish a global disease profile of MSP among drivers so that the regional data across different countries could be compared (Joseph et al. 2020). Therefore, the current study findings was compared against the global meta-prevalence data. The global meta-prevalence data of MSP in the back, neck and shoulder regions were $53 \%, 42.4 \%$ and $39.2 \%$, respectively, among the professional drivers (Joseph et al. 2020). However, the current study findings on the prevalence of MSP in the back, neck and shoulder regions were $80.7 \%, 81.9 \%$ and $48.1 \%$ which showed that the prevalence rate of MSP were much higher among the bus drivers in northern Thailand. The current findings on the prevalence rate of MSP was higher when compared to the only available study conducted locally in Thailand (Chirdsanguan and Sithisarankul 2019), however the bus driver in that population were short distance city bus drivers whereas the drivers who participated in the current study were long distance inter-city drivers. The SMART drive project also generated a meta-prevalence rate of MSP using sub-group analysis for light-moderate and heavy vehicle drivers (Joseph et al. 2020). When compared to the meta-prevalence rate of MSP in the back (56.6\%), neck $(38.1 \%)$ and shoulder regions (35.4\%) among the subgroups of heavy vehicle drivers, the prevalence rate of MSP in the current study was still seen to be much higher. The mean age of the bus drivers ( 44.18 years) in the current study was slightly higher when compared to the mean age of drivers (42.8 years) reported in the global prevalence study among drivers (Joseph et al. 2020). Besides that, the exact reasons for the higher prevalence rate reported in the current study was not clear. Moreover, the current study was designed as a cross-sectional study with an aim to investigate the prevalence of the MSP among professional drivers. Therefore, it was not possible to understand the reasons and risk factors for the high prevalence of MSP reported among the drivers. Evidence from epidemiological data suggests that WRMSDs are caused by various types of risk factors which include physical, psychosocial and individual risk factors (Calnan 2002). Thus, further studies on exploring the causal relationship between the risk factors and MSP are warranted among the bus drivers. An investigation is currently been conducted in Thailand by the SMART Drive network group to investigate various risk factors that are associated with MSP among the study population of the professional drivers.

The widely applied and recommended approach for estimating prevalence of MSP among drivers was 12 months 
Fig. 2 a Prevalence of MSP in the upper body region among bus drivers. b Prevalence of MSP in the lower body region among bus drivers

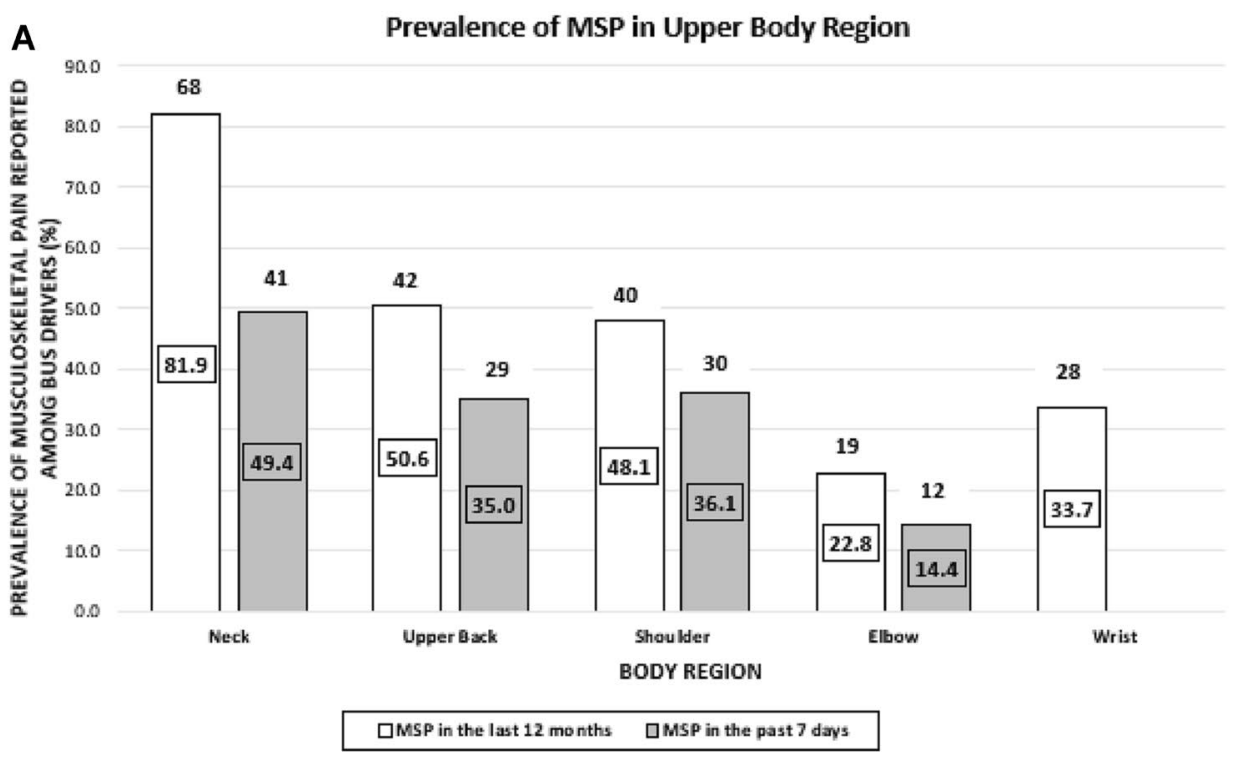

- Number of participants are indicated on the top of the boxes in the chart

- Percentage (\%) is indicated inside the boxes in the chart

B Prevalence of MSP in Lower Body Region

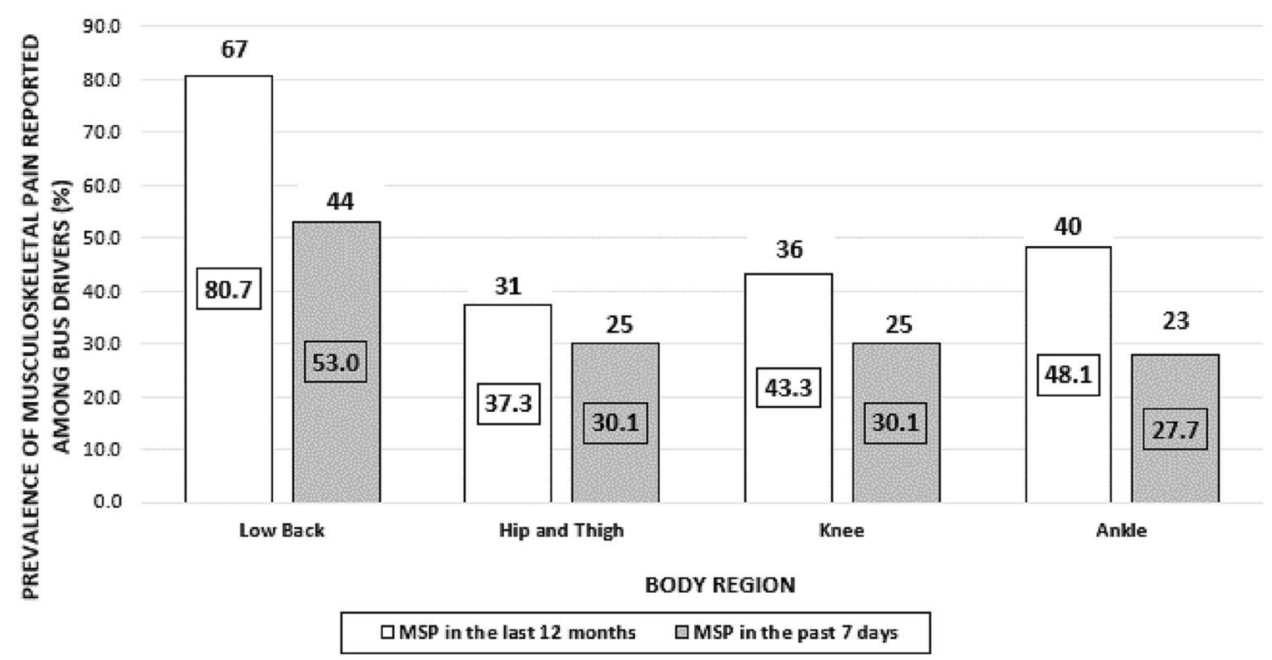

- Number of participants are indicated on the top of the boxes in the chart

- Percentage (\%) is indicated inside the boxes in the chart
Table 4 Severity of disability associated with low back pain evaluated by ODI scores among bus drivers

\begin{tabular}{lrl}
\hline $\begin{array}{l}\text { Number of participants } \\
-N(\%)\end{array}$ & Mean \pm SD & Severity of disability \\
\hline $46(68.7 \%)$ & $7.26 \pm 6.95$ & Minimal disability \\
$16(23.9 \%)$ & $29.75 \pm 5.74$ & Moderate disability \\
$4(6 \%)$ & $46.50 \pm 3.78$ & Severe disability \\
$1(1.5 \%)$ & $68.00 \pm 0.00$ & Crippled \\
\hline
\end{tabular}

Table 5 Severity of disability associated with neck back pain evaluated by NDI scores among bus drivers

\begin{tabular}{lrl}
\hline $\begin{array}{l}\text { Number of participants } \\
-N(\%)\end{array}$ & Mean \pm SD & Severity of disability \\
\hline $21(30.9 \%)$ & $2.38 \pm 1.36$ & No disability \\
$37(54.4 \%)$ & $8.05 \pm 2.52$ & Mild disability \\
$10(14.7 \%)$ & $17.60 \pm 2.12$ & Moderate disability \\
\hline
\end{tabular}


prevalence (Joseph et al. 2020). Therefore, the current study considered reporting MSP at 12 months period prevalence in addition to an acute prevalence of 7 days. Within the epidemiological studies that self-reported prevalence of MSP, longer prevalence periods increase the likelihood of participants recalling unpleasant experiences due to MSP (Hoy et al. 2012). The unpleasant experience associated with longer prevalence periods of MSP was supported in current study as the drivers reported a higher prevalence of MSP in 12 months than 7 weeks (Fig. 1a, b). Additionally, the disability associated with the back, neck and shoulder regions were evaluated to understand the experience of the drivers with MSP and its impacts on their daily activities. As there is a paucity of information available in the literature on the extent of disability associated with MSP among bus drivers, the disability levels reported by the bus drivers in the current study was not comparable. Nonetheless, the bus drivers reported mild to moderate levels of disability due to the MSP and most of the drivers were still continue to work with discomfort. This raise concerns on the welfare and safety of the drivers and their passengers, and this concerns needs to be highlighted with the stakeholders and policy makers during the discussion forum calling for appropriate prevention and management strategies of MSP.

The study has some limitations. The epidemiological data were collected from a small population of bus drivers from a particular region in the northern Thailand and hence, the extensive application of the results to a wider population needs to be interpreted with caution. On the other hand, the strength of the study was that the findings provided a strong case for discussion with the relevant stakeholders to initiate a wider population-based data base and disease profile for MSP among bus drivers all over the Country. While the current study presented the prevalence of MSP among bus drivers, the risk factors associated with the MSP were not studied which could be a limitation in the study. Another limitation was that the current study provided only an epidemiological findings, but it lacked an understanding of the lived experience of the drivers with MSP. Nevertheless, the current study used disease specific disability scales such as ODI, NDI and SPADI to evaluate the disability associated with MSP. Further qualitative study exploring the lived experience of the bus drivers with MSP is needed to understand the participant's perspective of the MSP problems. Although the disability associated with MSP was evaluated in the study, the effects of MSP on the mental health and job satisfaction of the drivers were not considered in this study which could be another limitation. Future studies might need to consider the effect of MSP on the job satisfaction and job content among bus drivers.

\section{Conclusion}

The bus drivers had a high prevalence rate of MSP in the back, neck and shoulder regions. There was mild to moderate levels of disability associated with the MSP experienced by the drivers. The findings of the study raise a call for a national wide epidemiological database for monitoring and reporting prevalence of MSP among the bus drivers. Appropriate health care and rehabilitation programs are necessary for the prevention and management of MSP among the bus drivers.

Acknowledgements The authors express sincere thanks to the bus drivers, the supervisors and the managers of the bus company for their support in the study. This study was supported by an internal university research grant by the Faculty of Associated Medical Sciences and the Graduate School, Chiang Mai University, Chiang Mai, Thailand and the Rising Star Funding Award by the Research and Enterprise Office, University of Brighton, the United Kingdom

Author contributions All authors whose names appear on the submission made substantial contributions to the conception or design of the work; or the acquisition, analysis, or interpretation of data drafted the work or revised it critically for important intellectual content; approved the version to be published; and agree to be accountable for all aspects of the work in ensuring that questions related to the accuracy or integrity of any part of the work are appropriately investigated and resolved.

Funding This study was supported by an internal university research grant by the Faculty of Associated Medical Sciences and the Graduate School, Chiang Mai University, Chiang Mai, Thailand and the Rising Star Funding Award by the Research and Enterprise Office, University of Brighton, the United Kingdom.

Availability of data and material Data will be available upon request.

\section{Declarations}

Conflict of interest No conflict of interest to declare.

Ethical approval The study was ethically approved by a university institutional ethics committee (Ethical approval number: AMSEC62EX-014) as per the Helsinki declarations).

Consent to participate All the participants gave written consent prior to the participation in the study.

Consent for publication All participants and researchers have given consent for publication.

\section{References}

Abledu J, Abledu G (2012) Multiple logistic regression analysis of predictors of musculoskeletal disorders and disability among bank workers in Kumasi. Ghana J Ergonomics. https://doi. org/10.4172/2165-7556.1000111

Abledu J, Offei E, Abledu G (2014) Predictors of work-related musculoskeletal disorders among commercial minibus 
drivers in Accra Metropolis. Ghana Adva Epidemiol. https://doi. org/10.1155/2014/384279

Breckenridge JD, McAuley JH (2011) Shoulder pain and disability index (SPADI). J Physiother 57(3):197

Bureau of Labor Statistics. Chart 19: Incidence rate and number of injuries and illnesses due to musculoskeletal disorders by selected occupations, all ownerships, 2017. 2018. https://www.bls.gov/iif/ soii-chart-data-2017.htm\#BLS_table_19. Accessed: 11 May 2020.

Calnan M (2002) Musculoskeletal disorders and the workplace: low back and upper extremities panel on musculoskeletal disorders and the workplace. Int J Epidemiol. 31(3):702

Carman KL, Dardess P, Maurer M, Sofaer S, Adams K, Bechtel C et al (2013) Patient and family engagement: a framework for understanding the elements and developing interventions and policies. Health Aff 32(2):223-231

Chirdsanguan S, Sithisarankul P (2019) Prevalence and related factors of musculoskeletal discomfort among bus drivers of Bangkok Mass Transit Authority. Chula Med Bull 1(1):49-59

Clavisi O, Bragge P, Tavender E, Turner T, Gruen RL (2013) Effective stakeholder participation in setting research priorities using a Global Evidence Mapping approach. J Clin Epidemiol. 66(5):496-502

Crawford JO (2007) The Nordic musculoskeletal questionnaire. Occup Med 57(4):300-301

Fairbank JC, Pynsent PB (2000) The Oswestry disability index. Spine 25(22):2940-2953

Health and Safety Executive (HSE). Work-related musculoskeletal disorders (WRMSDs) statistics in Great Britain. 2015. https://www. qcs.co.uk/wp-content/uploads/2015/12/Work-related-Musculoske letal-Disorder-WRMSDs.pdf. Accessed: 11 May 2020.

Hoy D, Bain C, Williams G, March L, Brooks P, Blyth F et al (2012) A systematic review of the global prevalence of low back pain. Arthritis Rheum 64(6):2028-2037

Jitnarin N, Kosulwat V, Rojroongwasinkul N, Boonpraderm A, Haddock C, Poston W (2011) Prevalence of overweight and obesity in Thai population: results of the National Thai Food Consumption Survey. Eat Weight Disord 16(4):e242-e249

John L, Flin R, Mearns K (2006) Bus driver well-being review: 50 years of research. Trans Res Part F Traff Psychol Behav 9(2):89-114

Joseph L, Standen M, Paungmali A, Kuisma R, Sitilertpisan P, Pirunsan U (2020) Prevalence of musculoskeletal pain among professional drivers: a systematic review. J Occup Health 62(1):e12150
MacDermid JC, Walton DM, Avery S, Blanchard A, Etruw E, Mcalpine $C$ et al (2009) Measurement properties of the neck disability index: a systematic review. J Orthop Sports Phys Ther 39(5):400-417

Magnusson ML, Pope MH, Wilder DG, Areskoug B (1996) Are occupational drivers at an increased risk for developing musculoskeletal disorders? Spine 21(6):710-717

Manafò E, Petermann L, Vandall-Walker V, Mason-Lai P (2018) Patient and public engagement in priority setting: a systematic rapid review of the literature. PLoS ONE. https://doi.org/10.1371/ journal.pone.0193579

Payares K, Lugo LH, Morales V, Londoño A (2011) Validation in Colombia of the Oswestry disability questionnaire in patients with low back pain. Spine 36(26):E1730-E1735

Sheahan PJ, Nelson-Wong EJ, Fischer SL (2015) A review of culturally adapted versions of the Oswestry Disability Index: the adaptation process, construct validity, test-retest reliability and internal consistency. Disabil Rehabil 37(25):2367-2374

Szeto GP, Lam P (2007) Work-related musculoskeletal disorders in urban bus drivers of Hong Kong. J Occup Rehabil 17(2):181-198

Vernon H, Mior S (1991) The Neck Disability Index: a study of reliability and validity. J Manipulative Physiol Ther 14:409-415

Wei C, Gerberich SG, Ryan AD, Alexander BH, Church TR, Manser M (2017) Risk factors for unintentional occupational injury among urban transit bus drivers: a cohort longitudinal study. Ann Epidemiol 27(12):763-770

Westgaard R (2000) Work-related musculoskeletal complaints: some ergonomics challenges upon the start of a new century. Appl Ergon 31(6):569-580

World Health Organization. Regional Office for the Western Pacific. The Asia-Pacific Perspective: Redefining Obesity and Its Treatment. Sydney: Health Communications Australia; 2000.

World Health Organization. Country profiles: Global status report on road safety 2018. https://www.who.int/violence_injury_prevention /road_safety_status/report/country_profiles_all_en.pdf?ua $=1$. Accessed: 11 May 2020.

Publisher's Note Springer Nature remains neutral with regard to jurisdictional claims in published maps and institutional affiliations. 